\title{
LA BUROCRACIA INSERTA EN UN ENTORNO DINÁMICO
}

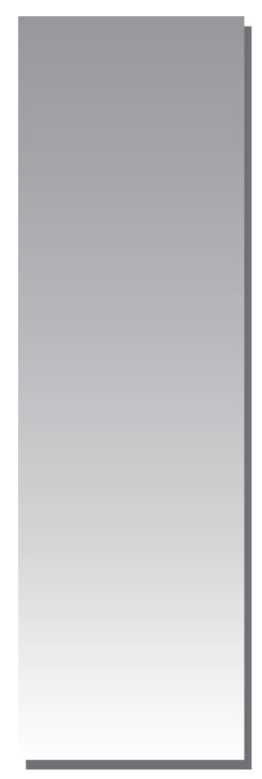

Enrique Huaco Pastor

E-mail: enrique_huaco@yahoo.com

\section{RESUMEN}

En la sociedad peruana, como en otras partes del mundo, los sectores públicos y privados están conformados por instituciones y empresas y durante el siglo pasado buena parte de ellas asumieron el modelo burocrático como forma de organización, que en la actualidad coexiste con otros modelos organizativos.

Los significativos cambios económicos, sociales, políticos y tecnológicos producidos en las últimas décadas en el mundo han generado que el modelo organizativo burocrático, con sus mejores cualidades, haya sido superado técnicamente por otros modelos flexibles y que pueden hacen frente con mayor eficiencia y eficacia a los nuevos desafíos de los entornos local, sectorial, nacional y global que se inscriben en una dinámica discontinua, de gran incertidumbre y excesivamente competitiva

Los modelos burocráticos en el sector privado que en el siglo XX, su periodo de auge, impulsaban una economía de escala creciente mediante el autocrecimiento o a través de las absorciones y fusiones, se autofragmentaron en las últimas décadas del siglo pasado, asumiendo formas organizativas articuladas en grupos empresariales, conformadas por organizaciones de menor tamaño, autónomas, con interdependencia e integradas entre ellas en red. De esa forma se desprendían de las estructuras burocráticas que generalmente poseían organigramas típicamente similares, piramidales, formalizados por normas excesivas y centralización en la toma de decisiones.

Los modelos burocráticos en el sector público en el extranjero, principalmente en Europa, incorporaron el principio de la subsidiaridad trasladando al sector privado la exploración, la producción y distribución de bienes y la prestación servicios. En el Perú se operaron los procesos de regionalización y descentralización, así como el proceso de desconcentración y el de creación de nuevos ministerios con el consiguiente crecimiento de la administración pública y de las estructuras burocráticas.

Palabras Clave: Burocracia, Globalización, Competitividad, Corrupción, Administración Pública.

\footnotetext{
* Mg. en Administración por la UNMSM. Lic. en Cooperativismo por la Universidad Nacional de la Plata. Profesor Asociado
} de la UNMSM. 


\begin{abstract}
Peruvian society as elsewhere, public and private sectors are shaped by institutions and companies and many of them in the last century took on the bureaucratic model as a form of organization, and now coexist with other organizational models.

Significant economic, social, political and technological developments in recent decades in the world have created the bureaucratic organizational model with its best qualities, has been technically surpassed by other models that are flexible and can cope more efficiently and effectively to new challenges of the local environment, sectoral, national and global dynamics are part of a discontinuous, uncertainty and overly competitive Bureaucratic models in the private sector that the twentieth century, in its boom period drove increasing economies of scale through the self-growth, or through takeovers and mergers, however in the last decades of the last century, fragmented self, articulated organizational forms taking business groups, formed by smaller organizations, autonomous, interdependent and integrated with each other in network., in this way had emerged from the bureaucratic structures, which generally had similar charts typically, pyramidal, formalized by excessive rules and centralization in decision-making. Bureaucratic models in the public sector in several foreign countries, mainly in Europe, incorporating the principle of subsidiarity moving to private sector exploration, production and distribution of goods and rendering services. In Peru, I operate the process of regionalization and decentralization and the devolution process and the creation of new ministries with the consequent growth of government and bureaucratic structures.
\end{abstract}

Key words: Bureaucracy, Globalization, Competitiveness, Corruption, Public Administrativa.

\section{INTRODUCCIÓN}

El proyecto de investigación plantea analizar el modelo de organización burocrático, revelando las barreras y anomalías de corrupción que ocasionan a sus usuarios, así como las causas estructurales de las que provienen sus efectos, identificando sus limitaciones y potencialidades con el objeto de -mediante enfoques y criterios modernos de la tecnología organizativa- proponer herramientas y mecanismos que contribuyan a la readapatacion del modelo burocrático, generando condiciones estructurales que hagan viable una prestación de servicios con estándares de productividad y calidad para sus usuarios y, en consecuencia, facilitando y promoviendo el desarrollo de sus colectividades, asi como el mejoramiento de su calidad de vida.

Otro objetivo es brindar un aporte de los avances de la tecnología de las Ciencias Administrativas a la modernizacion de la Administración Pública, en los ámbitos del gobierno nacional, gobiernos regionales y las municipalidades en su rol de gobiernos locales, congruente con el nuevo entorno social, económico y político, así como del nuevo marco juridico en el que se incriben las entidades públicas.

En estos ultimos años en el mundo y en el Perú se han producido acelerados cambios en la ciencia y tecnología, con impacto en el entorno económico, social, jurídico y político. En el caso peruano se viene operando un proceso de apertura e incentivos a las inversiones del sector privado, a la liberalización de la economía, al fomento del emprendimiento, la promoción de las micro y pequeñas empresas (MYPEs) y de las exportaciones. No obstante, las entidades del sector público que asumieron el modelo burocrático como forma de organización, en su desempeño vienen presentado barreras a las iniciativas del sector privado, limitando el crecimiento económico y la formalización de las unidades empresariales.

También encontramos manifestaciones de corrupción, situación problemática que demanda la reforma y modernizacion del aparato público, además de impulsar que se involucren en el desarrollo sostenible y armónico del Perú.

Los cambios en las entidades del gobierno nacional, regional y local imponen la necesidad de asumir estructuras organizativas modernas que promuevan y gestionen con estándares de productividad y competitividad, para que el Perú pueda alcanzar un crecimiento económico sostendo, así como mejores niveles y calidad de vida de sus colectividades. 
DISEÑO EXPERIMENTAL, MARCO TEÓRICO Y PLANTEAMIENTO DE HIPÓTESIS

\section{Diseño experimental}

El tipo de la investigación será de tipo descriptivo-explicativo por sus características.

\section{Metodología}

La metodología de investigación que se empleará es la demostración y contrastación de las hipótesis, correspondiendo a la metodología descriptiva-explicativa.

\section{Hipótesis}

El modelo burocrático de las entidades del sector público genera barreras a las iniciativas privadas y muestra manifestaciones de corrupción originadas por sus características estructurales. Conforman estructuras organizativas superadas por otras formas de organización, surgiendo la necesidad de proponer mecanismos que permitan la readaptacion del modelo burocrático, adoptando modelos alternativos con estándares de productividad y competitividad satisfactorios.

\section{MÉTODOS Y RESULTADOS}

La investigación se concentra en la identificación de las barreras burocráticas relevantes en la organizaciones del sector público que vienen ocasionando un lento avance del Perú para escalar posiciones en el Ranking de Competitividad, expresado en encuestas nacionales, y del Banco Mundial. Así también la presente investigación busca identificar las muestras de corrupción que surgen por el modelo burocrático y las actitudes burocráticas que adoptan las organizaciones del sector público.

La perspectiva del gobierno se manifiesta en la voluntad política del Poder Ejecutivo y del Poder Legislativo y se expresa en la promulgación de distintas leyes y normas legales; en los esfuerzos del gobierno por lograr su implantación; en la perspectiva de los académicos en materia de organización así como en los procedimientos para hacer frente a estas anomalías mediante distintas teorías o corrientes organizativas.

Finalmente, en el presente trabajo el investigador propone mecanismos que se orientan a readaptar el modelo organizacional burocrático a una nueva realidad empresarial organizativa, que se distingue por unas características determinadas, siendo sus factores claves de éxito los siguientes:

- Adecuación de las estructuras a la nueva situación competitiva en un entorno local, regional y globalizado.

- Adaptación de las organizaciones públicas para alcanzar una mayor satisfacción del cliente o usuario.

- Respuesta a la creciente complejidad organizativa y del entorno.

- Respuesta a los requerimientos y producción de servicios con estándares de productividad y calidad internacionales.

\section{ANÁLISIS Y DISCUSIÓN}

\section{Barreras burocráticas}

La administración pública peruana ha asumido en su organización la estructura formal burocrática, la misma que produce las barreras que dilatan los procedimientos, cuando en ejercicio de su poder público actúa como autoridad legítima y no como agente económico y promotor. También lo hace estableciendo actos y reglamentos administrativos que tienen por efecto impedir u obstaculizar el acceso o permanencia y desarrollo de los agentes económicos del sector privado en el mercado.

Las barreras burocráticas se manifiestan, generalmente, cuando las instituciones públicas imponen requisitos, obligaciones y cobros como exigencias o como impedimentos o limitaciones a la actuación de los agentes económicos.

La Comisión de Acceso al Mercado del Instituto Nacional de Defensa de la Competencia y Protección de la Propiedad Intelectual (INDECOPI) distingue como causas de esos efectos a dos tipos de dichas barreras: las ilegales y las denominadas irracionales.

Las primeras ocurren cuando se produce la barrera sin haber competencia legal que la sustente, mientras que las segundas suceden cuando el acto, la disposición o las exigencias que de ella se derivan son contrarios a las prácticas y principios de orden lógico, razonable y proporcional. Dichas anomalías están expresadas y normadas en los Textos Únicos de Procedimientos Administrativos (TUPA) de las distintas instituciones que compo- 
nen la administración pública. Dichas barreras burocráticas también conforman fuentes proclives a que se generen acciones de corrupción.

De Soto en su libro "El Otro Sendero" publicado en 1983, llegó a la conclusión de que el exceso de regulaciones gubernamentales en el Perú (unas 28,000 por año entre leyes, decretos, ordenanzas y reglas) obliga a los ricos a sobornar a los funcionarios públicos, y condena a los pobres a trabajar en la informalidad, fuera del marco legal de sus países.

Según un estudio del Banco Mundial, hacen falta 15 trámites y 68 días para registrar una empresa -aunque sea de un único empleado- en la Argentina; 18 trámites y 67 días en Bolivia; 15 trámites y 152 días en Brasil; 10 trámites y 28 días en Chile; 14 trámites y 90 días en Ecuador; 12 trámites y 115 días en El Salvador, y 7 trámites y 51 días en México. En cambio en Australia hacen falta sólo 2 trámites que se hacen en 2 días para registrar una empresa, y en Estados Unidos se requieren solo 5 trámites que se hacen en 4 días.

Una de las autoras del ranking de la burocracia es la doctora Sylvia Solf del Banco Mundial a quien se le formuló la pregunta ¿a qué se debe que la mayoría de los países latinoamericanos se están quedando atrás en el ranking del Banco Mundial de los países con menos trabas burocráticas para hacer negocios? Su respuesta fue la siguiente: "No es porque los países latinoamericanos se estén rehusando a reducir los trámites burocráticos, sino que China y otros países asiáticos, del Este de Europa y África están eliminando la burocracia mucho más rápido. En materia de los trámites requeridos para exportar un producto, en Argentina y Paraguay se deben llenar nueve formularios, ocho en Venezuela y siete en Perú. Comparativamente, se deben llenar dos formularios en Francia y cuatro en Estados Unidos"

En un ranking que mide la facilidad de hacer negocios en los 181 países incluidos en el estudio, los países latinoamericanos que salen mejor parados son Chile (en el puesto 40 a nivel mundial), Antigua y Barbuda (puesto 42), Colombia (ubicación 53), México (puesto 56) y Perú (lugar 62). Salvo Colombia, los demás países latinoamericanos recién mencionados perdieron posiciones respecto del año pasado.

En el Perú, la mayoría de peruanos es víctima de las altas barreras burocráticas. A pesar de ello, el espíritu emprendedor no se ha perdido y es uno de los más representativos en el mundo.

\section{Emprendimiento}

El reporte del Monitor Global del Emprendimiento (GEM por sus siglas en inglés) es elaborado por el Babson College y el London Business School of Economics y mide el grado de emprendimiento de 43 países desde el año 2001 hasta la fecha.

Así, en el 2008 el Perú ocupa el segundo lugar mundial de actividad emprendedora, con una tasa de 25.6\%. Bolivia se sitúa en el primer puesto, con $29.8 \%$, mientras que Colombia se ubica en la tercera casilla, con $24.5 \%$. Chile tiene una tasa de $14.1 \%$, mientras que Estados Unidos, un $10.8 \%$.

El informe destaca además que nuestro país, junto con Colombia, China y Chile, exhibe los más altos niveles de expectativas de emprendimiento en el grupo de economías impulsadas por la eficiencia, ubicados en un nivel intermedio entre aquellas naciones desarrolladas (innovadoras) y las que son impulsadas por el requerimiento en la producción de materias primas.

Según el estudio, el Perú tampoco se ubica entre los países que ejecutaron reformas (entre 2007 y 2008) para simplificar los procesos burocráticos, como la creación de ventanillas únicas, la introducción de procedimientos de inscripción en línea, y la reducción o eliminación de la exigencia de capital mínimo para abrir un negocio.

Otro de los puntos más complicados para la apertura de empresas es la entrega de licencias de funcionamiento de establecimientos comerciales y de construcción por parte de las municipalidades. La Cámara de Comercio de Lima informó que, según las estadísticas del INDECOPI, durante el cuarto trimestre de 2008, el 55\% de las barreras identificadas corresponden al otorgamiento de licencias municipales de funcionamiento de establecimientos comerciales.

No obstante, otro resultado alentador antes de la crisis financiera del 2009 es que el 60\% de los peruanos consultados por las Cámaras de Comercio ve oportunidades para abrir un negocio en los próximos seis meses, lo que nos ubica en el cuarto lugar mundial (compartido con Sudáfrica), solo superados por Angola, con el 74\%; Dinamarca, con $69 \%$, y Colombia, con el 65\%. Después de la crisis, el 34\% de los peruanos observa la posibilidad de abrir su propia empresa, resultado que se obtiene a despecho del pesimismo del sector privado por el avance de la crisis financiera internacional.

No obstante, el último estudio Doing Business 2009, elaborado por el Banco Mundial, revela 
que el Perú cayó en la clasificación mundial de naciones que facilitan hacer negocios, al pasar del puesto 53 al 62 entre un total de 181 países.

Sandra Doig, Directora del Consejo Nacional de Competitividad, informó en agosto del 2010 que un mes después presentaría un reporte al Banco Mundial demostrando el avance del país del puesto 56 al puesto 40 , al haber presentado13 reformas de simplificación de procedimientos, entre ellos el de la modificación del Sistema Nacional de Inversión Pública (SNIP), incorporando los temas de innovación y de tecnología en los proyectos de inversión.

\section{El reporte señala que:}

"En muchas economías, los procedimientos para la creación y reconocimiento legal de una empresa, como los que analiza Doing Business, son tan complicados que los emprendedores prefieren renunciar a la legalidad y operar en el sector informal. Un procedimiento sencillo de apertura estimula la creación de nuevas empresas".

Asimismo, indicó que de las 34 denuncias por barreras burocráticas iniciadas en el último trimestre del 2008 , se constata que el $56 \%$ es contra las municipalidades y que el $44 \%$ corresponde al Gobierno central.

Así tenemos que en cuanto a las barreras a la formalización, abrir una empresa en el Perú toma 41 días y cuesta un 25\% del PBI per cápita, considerando que el 50\% de estas barreras está en el ámbito municipal. Respecto a las barreras a la inversión el informe indica que obtener un permiso de construcción en nuestro país demora 205 días y cuesta un $130 \%$ del PBI per cápita, donde el $42 \%$ de estas barreras está en el ámbito municipal.

Según el informe de la Corporación Financiera Internacional del Banco Mundial, varios países latinoamericanos, entre ellos el Perú, son los campeones mundiales de la burocracia, mientras que los países de Europa, Asia y África están actuando con mayor rapidez.

El Banco Mundial y el gobierno de Estados Unidos están empezando a descubrir lo que Hernando de Soto, conocido economista peruano, viene diciendo desde hace veinte años: que gran parte de la corrupción en América Latina, Asia y África se debe a un exceso de regulaciones gubernamentales.

En un nuevo estudio, el Banco Mundial analizó cuántos trámites burocráticos deben hacer los ciudadanos de varios países de todo el mundo para registrar un pequeño negocio. Y descubrió, entre otras cosas, que los países con la mayor cantidad de regulaciones son aquellos en los que la gente tiene que pagar más sobornos y donde hay mayor corrupción.

El estudio "Haciendo Negocios en el 2004" contiene datos fascinantes ya que realizaron el mismo experimento que el economista peruano Hernando de Soto realizó hace dos décadas. De Soto investigó cuántos trámites burocráticos hacían falta para abrir una pequeña empresa de confecciones de apenas un empleado en Lima, y descubrió que era casi imposible hacerlo de acuerdo con la ley: le hubiera llevado 289 días y US\$ 1,231 , el equivalente a tres años del salario mínimo de la época.

Si nos ubicamos en el ranking de cómo los efectos de las barreras burocráticas se aúnan con algunas muestras de corrupción, el Banco Mundial expresa que los países que tienen la mayor cantidad de regulaciones gubernamentales del mundo son Haití, Paraguay, Bolivia, Ecuador y Honduras. No es de sorprender que estos mismos países figuren entre los que tienen la mayor percepción de corrupción en el nuevo ranking de Transparencia Internacional, el grupo anticorrupción cuya sede está en Alemania.

Hernando De Soto, en una entrevista con Andrés Oppenheimer, manifestó que se corroboró lo que siempre pensó: que las principales causas de la corrupción no son culturales, ni biológicas, sino políticas. Cuando los países aprueban leyes que son absurdas, la gente va a burlarlas. Las leyes que son difíciles de cumplir son posiblemente la principal fuente de corrupción en el mundo.

El economista peruano está terminando una nueva investigación en Egipto, México, Filipinas, Haití y Honduras. Para el año próximo, estará asesorando a 21 países, incluida Rusia, sobre cómo reducir sus laberintos regulatorios. "En los gobiernos de América Latina las regulaciones frecuentemente han sido trabas al desarrollo en lugar de facilitadoras del desarrollo y muchas de ellas podrían reducirse".

Mientras tanto De Soto sigue adelante con su nuevo proyecto: ayudar a los países a darles títulos de propiedad a cientos de millones de pobres que no pueden abrir un negocio o abrir una empresa casera porque ni siquiera tienen títulos legales sobre sus viviendas. Al no tener títulos de propiedad legales ni siquiera pueden 
sacar un crédito bancario de US\$ 50 para comprar una máquina de coser o herramientas para abrir un pequeño taller hogareño. En su opinión, otro modo de incentivar el espíritu emprendedor del país es mediante la educación, la implementación de programas de asesoría para la microempresa $\mathrm{y}$, por parte del sector privado, mayores políticas de subcontratación de pequeños proveedores.

A continuación, podemos apreciar el ranking de los países sudamericanos en función de sus regulaciones y el libre mercado (ver Tabla $\mathrm{N}^{\circ} 1$ ).

Si bien en algunos puntajes el Perú quedó bastante bajo, en general estamos en una posición bastante buena, terceros a nivel sudamericano en este ranking. Se ha mejorado mucho en estos aspectos en los últimos años pero es necesario trabajar mucho más para que nuestro país pueda continuar creciendo y desarrollándose tanto a mediano como largo plazo.

Respecto a los trámites para exportar un producto, se deben llenar nueve formularios en Argentina y Paraguay, ocho en Venezuela y siete en Perú. En cambio, se requieren dos formularios en Francia y cuatro en Estados Unidos.

La Ley de Simplificación Administrativa, Ley $\mathrm{N}^{\circ} 25035$, aprobada paradójicamente por unanimidad en un contexto de extrema sobreregulación económica, fue resultado de la influencia de las investigaciones del Instituto Libertad y Democracia (ILD), que pusieron en evidencia la burocratización como principal causa de la informalidad en la economía del país. Esta ley incorporó al ordenamiento jurídico importantes principios orientadores para la administración pública, así como normas de protección al ciudadano de aplicación concreta. Se eliminaron requisitos innecesarios, como documentos que la entidad ya poseía, y se permitió la presentación de declaraciones juradas en lugar de los documentos originales, con cargo a una fiscalización posterior. La difusión de esta ley tuvo un fuerte impacto en los ciudadanos que empezaron a tomar conciencia de sus derechos y a exigirlos en las ventanillas al amparo de la ley.

Así mismo la Ley Marco para el Crecimiento de la Inversión Privada fue una respuesta a la coyuntura de reformas económicas adoptadas en el país y a la necesidad de que las entidades estatales ayudaran, con su eficiencia y eficacia, a atraer la necesaria inversión privada, nacional y extranjera, que contribuyera a la generación de empleo, valor agregado y bienestar en el Perú. Esta ley estableció para toda entidad pública la obligación de aprobar anualmente su Texto Único de Procedimientos Administrativos (TUPA). El TUPA es un listado de todos los procedimientos, requisitos y cobros que una dependencia pública puede trasladar al ciudadano. Por ello, el TUPA es un mecanismo de información para evitar exigencias y formalidades costosas y, a la vez, es un instrumento contra la arbitrariedad del funcionario público, no pudiendo éste exigir requisitos ni cobros adicionales a los que el TUPA establece. Desde la expedición de la Ley Marco para el Crecimiento de la Inversión Privada poco a poco se ha ido desarrollando en la administración pública la costumbre de elaborar los TUPA y entre los particulares de utilizarlos como fuente de información y como instrumento para defenderse de arbitrariedades.

Tabla $\mathbf{N}^{\circ}$ 1. Ranking de los países sudamericanos en función de sus regulaciones y el libre mercado

\begin{tabular}{|l|c|c|c|c|c|c|c|c|c|c|c|}
\hline \multicolumn{1}{|c|}{ País } & $\begin{array}{c}\text { Puntaje } \\
\text { Global }\end{array}$ & $\begin{array}{c}\text { Libertad } \\
\text { de } \\
\text { Negocios } \\
\text { / Empresa }\end{array}$ & $\begin{array}{c}\text { Libertad } \\
\text { Comercio }\end{array}$ & $\begin{array}{c}\text { Libertad } \\
\text { Fiscal }\end{array}$ & $\begin{array}{c}\text { Tamaño } \\
\text { Gobierno }\end{array}$ & $\begin{array}{c}\text { Libertad } \\
\text { Monetaria }\end{array}$ & $\begin{array}{c}\text { Liber- } \\
\text { tad de } \\
\text { Inver- } \\
\text { sión }\end{array}$ & $\begin{array}{c}\text { Liber- } \\
\text { tad } \\
\text { Finan- } \\
\text { ciera }\end{array}$ & $\begin{array}{c}\text { Dere- } \\
\text { chos de } \\
\text { Propie- } \\
\text { dad }\end{array}$ & $\begin{array}{c}\text { Libertad } \\
\text { ante la } \\
\text { Corrupción }\end{array}$ & $\begin{array}{c}\text { Liber- } \\
\text { tad de } \\
\text { Traba- } \\
\text { jo }\end{array}$ \\
\hline Chile & 78.3 & 66.3 & 85.8 & 78.2 & 90.1 & 77.3 & 80 & 70 & 90 & 70 & 75 \\
\hline Uruguay & 69.1 & 65.6 & 83.4 & 82.2 & 76.5 & 72.8 & 70 & 30 & 70 & 67 & 73.6 \\
\hline Perú & 64.6 & 65.1 & 79.4 & 79.7 & 91.8 & 86.5 & 60 & 60 & 40 & 35 & 48.7 \\
\hline Colombia & 62.3 & 77.4 & 72.4 & 72.9 & 65.9 & 70.6 & 60 & 60 & 40 & 38 & 66 \\
\hline Paraguay & 61 & 61.7 & 83.6 & 96.6 & 90.4 & 76.7 & 60 & 60 & 30 & 24 & 27 \\
\hline Brazil & 56.7 & 54.4 & 71.6 & 65.8 & 50.3 & 77.2 & 50 & 50 & 50 & 35 & 62.7 \\
\hline Bolivia & 53.6 & 58.5 & 81.8 & 84.8 & 71.9 & 67.9 & 20 & 60 & 20 & 29 & 41.9 \\
\hline Ecuador & 52.5 & 54 & 72.6 & 85.8 & 83.2 & 75 & 30 & 40 & 25 & 21 & 38.3 \\
\hline Argentina & 52.3 & 62.1 & 70 & 70.3 & 75.6 & 60.6 & 50 & 40 & 20 & 29 & 45.6 \\
\hline Venezuela & 39.9 & 50.8 & 59.6 & 70.6 & 69.3 & 53.7 & 10 & 30 & 5 & 20 & 30.1 \\
\hline
\end{tabular}


Por otro lado, con la creación del Instituto Nacional de la Competencia y Protección de la Propiedad Intelectual (INDECOPI) como la entidad encargada de proteger la economía de mercado y la libre competencia, se asignó a una de sus comisiones (hoy la Comisión de Acceso al Mercado) la tarea de velar por el cumplimiento de las normas relacionadas con la eliminación de barreras burocráticas y la simplificación administrativa, entre ellas lo relacionado a los TUPA. Se atribuyó a esta comisión la facultad de investigar las infracciones, de oficio o a petición de parte, y producir un informe técnico a ser resuelto por la Presidencia del Consejo de Ministros (PCM) si la infracción se origina en normas del Poder Ejecutivo, o los respectivos Consejos Regionales o Concejos Municipales, según el caso. La instancia correspondiente tiene 30 días para pronunciarse sobre el informe presentado por la Comisión de Acceso al Mercado. Si dentro de ese plazo no emite pronunciamiento alguno, se entenderá fundada la denuncia y la barrera será inaplicable al caso concreto. Si el pronunciamiento de la instancia respectiva es contrario a la opinión del INDECOPI, esta entidad puede interponer ante el Poder Judicial una demanda de acción popular; o, si la barrera cuestionada se impuso a través de ordenanzas municipales o cualquier otra norma regionales de carácter general, INDECOPI remitirá los actuados a la Defensoría del Pueblo para que ésta inicie una demanda de inconstitucionalidad. En algunas de sus resoluciones, esta Comisión expresa "criterios de observancia obligatoria" sobre aspectos tales como el análisis de racionalidad de una barrera burocrática, licencias municipales y principio de la legalidad que, adecuadamente difundidos, deberían orientar a las entidades públicas.

En el mes de febrero del 2010 la Comisión de Eliminación de las Barreras Burocráticas del INDECOPI señaló que el 79\% (154) de las Municipalidades Provinciales no publicaron su Texto Único de Procedimientos Administrativos (TUPA) durante el año 2009, y la Cámara de Comercio de Lima expresó que dicha omisión afecta la formalización e impide la competitividad.

En los primeros días del mes de junio del 2010, el pleno del Congreso aprobó una serie de medidas orientadas a impulsar la inversión privada y que al mismo tiempo permitirían avanzar en el Ranking Doing Business en el 2011, donde se aprueba la propuesta de simplificación de procedimientos que fuera elaborada por el Consejo
Nacional de Competitividad, así como las facilidades para la constitución, inscripción y legalización de microempresas, mediante un deposito del $25 \%$ del capital social.

El World Economic Forum de Ginebra (Suiza), respecto al Índice Global de Competitividad 20102011, ubica al Perú en el puesto 73 del estudio comparativo de la competitividad de 130 economías del mundo, habiendo escalado cinco puestos en el periodo 2009-2010. En comparación con los demás países de América Latina y El Caribe, el Perú aparece en la mitad de la tabla, detrás de Brasil, Uruguay, México y Colombia.

El ex ministro de Economía, Pedro Pablo Kuczynski, en su columna dominical del 07 de febrero del 2010 manifestó lo siguiente:
"En la medida en que el emprendimiento sea más por vocación que por necesidad, que no es el caso del Perú, se resolverá el alto índice de mortalidad de las empresas que recién empiezan, pues hará que estas sean viables, no se queden en la informalidad y contribuyan más en el desarrollo del país... Los problemas en el Perú son retos de organización y proble- mas económicos: en el sector salud (Essalud y el Ministerio de Salud - MINSA) los médicos tienen que recurrir a cachuelos y hacen que en muchos casos los pacientes en atención terminen en emergencias... La principal reforma debe referirse a la empresa del agua (SEDAPAL), pues dejan de cobrar y pierden el $40 \%$ del agua que producen."

El caso de SEDAPAL es emblemático en el tema de la burocracia. En principio, el servicio que suministra es a nivel nacional y la cobertura del agua potable llega al $77 \%$ de la población mientras que en saneamiento llega al $62 \%$. Ni qué decir de la falta de continuidad: en muchos lugares del país el agua potable se corta por un promedio de 17.8 horas diarias. Para abordar esta problemática y alcanzar un nivel de calidad aceptable, el IPE ha calculado que es necesario invertir US\$ 4,062 millones durante los próximos diez años; de los cuales el $49 \%$ corresponde solamente a las inversiones que SEDAPAL tiene atrasadas.

Este escenario negativo se vería confirmado por una evaluación independiente que encargó el Ministerio de Economía y Finanzas (MEF) hace poco sobre el programa Agua para Todos. Respecto a la burocracia y a los actos de corrupción que de ella se desprenden como efecto colateral, 
caracterizaremos algunas anomalías de este programa. La primera es que su oficina comercial del cono norte de Lima atiende a un aproximado de 1,000 usuarios diariamente, lo que ha generado 10 cubículos y 10 empleados y 20 vigilantes involucrados en forma directa para atender los distintos reclamos de los usuarios, en su mayoría por facturaciones atípicas, quienes para ejercitar su derecho de reclamo forman colas de tres cuadras, para obtener un formato en el que tienen que consignar en dos líneas el reclamo que tienen. Fácilmente percibimos que en esta empresa del Estado todavía no han penetrado los servicios de Internet, $\mathrm{y}$ se ha remplazado el papel sellado de uso común de los siglos XIX y XX por el formato indicado. También presentan deficiencias como la falta de mantenimiento de las redes de tuberías y de las matrices, ocasionando inundaciones continuas, con la consiguiente pérdida de agua y fugas del elemento en los exteriores de los predios. Así mismo en la realización de licitaciones se han efectuado denuncias de corrupción, entre ellas el proyecto de tratamiento de aguas residuales de San Bartolo por la concesión otorgada a una empresa brasilera de reciente constitución, que fue violentando las normas de compras del Estado, adjudicada en agosto del 2010. Al respecto, la Contraloría General de la República ha denunciado al Directorio y a los funcionarios de la Municipalidad de San Bartolo por corrupción. También hay continuas denuncias por las pésimas compras de tuberías y medidores de material obsoletos, cómo el plomo en lugar de dar preferencia al PVC.

Se ha denunciado al régimen toledista y al presente régimen aprista por la frivolidad de sus burócratas que dispendiaban millones de dólares del erario nacional en viajes de turismo a los lugares más exóticos del mundo. En los últimos 15 años no conozco un solo caso de un alto burócrata moderno, técnico y profesional, que haya renunciado por tener discrepancias con el uso indebido de los dineros del Estado, que son de todos los peruanos.

En el 2009 los presidentes de las regiones denunciaron que en la Dirección General de Programación Multianual (DGPM), que depende del Ministerio de Economía y Finanzas, se genera un cuello de botella para aprobar los proyectos, especialmente los que requieren importantes sumas de dinero; por eso culpan al gobierno central por generar trabas burocráticas.
En medio del enfrentamiento en diversas instancias del Estado, lo real es que las obras se ejecutan a paso lento. Cabe invocar que no se excedan los plazos para la evaluación de proyectos o, peor aun, que supongan que no hay límites para aprobarlos. Es necesario que se difundan profusamente los mecanismos para acceder a estos programas. Mientras exista transparencia habrá posibilidades de detectar tentativas de corruptelas.

Durante la visita del consultor internacional Michael Porter en el 2010, éste fue enfático en señalar que "la pobreza expresa nuestra competitividad por la extensión innecesaria de los procedimientos administrativos de las instituciones públicas".

El Centro Nacional de Planeamiento Estratégico (CEPLAN), en su labor de diagnóstico para la formulación de los lineamientos estratégicos para el desarrollo nacional 2010-2012, expresa que los cambios en la administración publica implementados por el régimen aprista no han sido los suficientes para garantizar la eficiencia de la gestión pública: presupuestalmente el gasto en los sectores productivos es proporcionalmente menor frente al incremento del gasto en los sectores sociales. Al respecto la Comisión Interministerial de Asuntos Sociales (CIAS) señala que existen una serie de deficiencias de gestión en la aplicación de los recursos, temas de corrupción denunciados repetidamente por los medios de comunicación masiva.

Así también se reconoce que aun esta pendiente la reforma integral del Estado, debiendo resaltar que dicha reforma está amparada por la Ley Marco de la Modernización del Estado, en las leyes relacionadas con la descentralización y regionalización, de transparencia y acceso a la información pública.

Hace unos meses (enero del 2010), el presidente Alan García criticó a sus propios colaboradores directos (los ministros) diciendo que no tienen la energía ni la pasión para exigir rapidez, y por eso se debe dar un manazo (golpe) sobre la mesa para que la inversión se efectúe en menos tiempo; así dispuso la implantación de los Núcleos Ejecutores, manifestando que es una forma de brindar democracia y descentralización popular

Para el titular de la cartera de Vivienda, los cambios permitirán acelerar la ejecución de 7,500 proyectos de hasta US\$ 1.9 millones, que 
podrían ser aprobados apenas con un estudio de preinversión.

El Ministerio de Comercio Exterior y Turismo (MINCETUR) anunció en el mes febrero del 2010 la publicación del Reglamento de la Ventanilla Única de Comercio Exterior (VUCE) con el cual será obligatorio que los trámites de importaciones y exportaciones se efectúen por esta vía. De esta forma los usuarios del comercio exterior ahorrarán US\$ 3.5 millones al año, debido a que podrán realizar en un solo lugar unos cien procedimientos correspondientes a diversas entidades públicas (Ministerio de la Producción, Ministerio de Transportes, Instituto Tecnológico del Perú, Dirección General de Medicamentos, Servicio Nacional de Sanidad Agraria, Dirección Nacional de Salud Ambiental, entre otros). Igualmente para febrero del 2010 se anunció la publicación del nuevo texto único de simplificación de procedimientos administrativos de los Ministerios de Producción, Transporte, Salud, Trabajo, Justicia, y Energía y Minas.

En los primeros seis meses del 2010 INDECOPI inició 90 procesos contra la imposición de barreras burocráticas, reportando un incremento del $26 \%$ con respecto a las denuncias presentadas en el primer semestre del 2009. El 48\% de ellas han correspondido a los gobiernos locales y la mayor parte de esas denuncias corresponden a las licencias de funcionamiento.

A partir del segundo semestre del 2010 las municipalidades podrán acceder a plataformas virtuales para simplificar sus trámites, lo anunció la Directora del Consejo Nacional de Competitividad (CNC). De esta forma una empresa podrá constituirse, tener su RUC, su clave y recibir su Licencia de Funcionamiento en un lapso de ocho a diez días, cuando en el mes de mayo del 2010 estos trámites demoraban 41 días en promedio, en el mejor de los casos.

La mejora de la competitividad incluye dos elementos que forman parte de la medición del Foro Económico Mundial como son un nuevo y eficiente sistema de calidad, y el impulso a la innovación en las empresas. Así tenemos varias acciones realizadas:

- En julio del 2010 el Consejo Nacional de Competitividad reconoció que el Programa de Modernización de las Municipalidades ha permitido una significativa simplificación de procedimientos, disminuyendo el tiempo de otorgamiento de las licencias de funcionamiento y de las licencias de construcción, pero también reconoce que en muchas municipalidades los importes por esos servicios se han incrementado

- El 28 de julio del 2010, en las Normas Legales, el Poder Ejecutivo redujo los trámites para la constitución de las microempresas, reduciendo significativamente los costos para su reconocimiento.

En los primeros días del mes de noviembre del 2010 el Banco Mundial informó que el Perú avanzó 10 puestos en el Ranking Doing Business, ubicándose en la posición 36. Dicha institución también destacó que el país ha emprendido reformas en el clima de negocios en América Latina, facilitando el comercio exterior y simplificando la atención en la expedición de licencias para la apertura de establecimientos comerciales y de construcción.

Reconocemos el esfuerzo del gobierno por abrir canales de asistencia financiera para emprendedores en épocas de crisis, pero hay que poner el ojo en la burocracia para ver si está a la altura de las circunstancias. Es importante destacar que el gobierno también ha implantado incentivos a favor de las microempresas como el Programa de Compras Estatales y las líneas de financiamiento para la exportación, eslabón que consideramos importante para que la cadena productiva sea realmente potenciada ya que esta es la parte floja de la burocracia responsable del trámite y es una incógnita sobre si aun es necesario palanquear la economía con este tipo de programas

\section{LA BUROCRACIA Y LA CORRUPCIÓN}

El 94\% de los habitantes de Lima considera que la corrupción es un problema grave o muy grave en nuestro país. Sólo el 5\% cree que es poco o nada grave. Así lo revela la encuesta del Instituto de Opinión Pública (IOP) de la Universidad Católica realizada en Lima Metropolitana entre el 29 de abril y el 02 de mayo del 2010.

Un aspecto descollante es la definición que dan los encuestados al fenómeno de la corrupción: $24 \%$ dice que consiste en apropiarse de dinero o propiedades públicas; un 15\% dice que consiste en conseguir beneficios particulares aprovechando un cargo público. Otras respuestas aprietan la yugular del régimen: promover campañas de solidaridad (en caso de terremotos, etc.) y quedarse con lo entregado (15\%); contratar a sus allegados 
y/o parientes (12\%); hacer obras públicas en tiempo de campaña (11\%). Para los encuestados, corrupción también es hacer una gestión diferente a la prometida en campaña (9\%) y despedir a los funcionarios encontrados al asumir el cargo (4\%).

Cuando la consulta buscó ubicar los centros de la corrupción, el Congreso encabeza la lista negra ya que un $79 \%$ de los encuestados lo considera corrupto o muy corrupto; el Poder Judicial sale segundo, con $73 \%$, mientras que el gobierno en su conjunto obtiene $71 \%$.

Los datos señalan una desaprobación en ascenso respecto al gobierno actual. En agosto de 2008 , recuerda el IOP, un $10 \%$ consideraba a este régimen más corrupto que los otros; ahora ese veredicto alcanza el $20 \%$. A eso hay que añadirle el $50 \%$ que opina que este gobierno es tan corrupto como los otros. De Ripley: hay quienes creen que la administración actual no es corrupta, pero sólo son el $0.4 \%$ del total.

Aquello de que nuestro pueblo no tiene memoria es desmentido por la encuesta. Así, en respuesta a la pregunta: ¿En cuál de los gobiernos que usted recuerda cree que hubo más corrupción? Alberto Fujimori (1990-2001) ocupa el primer lugar (44\%); Alan García (1985-1990) llega segundo, con 34\%, y Alejandro Toledo (2001-2006) pasa al tercer puesto, con $7 \%$.

Un ángulo sombrío es el que se refiere al peruano en su totalidad (incluidos, por cierto, los encuestados). Reza la pregunta: En general, ¿cuán honesto diría usted que es el peruano? Sólo el 27\% respondió: muy honesto / algo honesto, mientras que el $71 \%$ cree que es poco honesto / nada honesto. Hay en esto una suerte de confesión colectiva, a escala de Lima. Es doloroso, porque significa que la deshonestidad es un mal extendido, casi una enfermedad crónica. Un $25 \%$ considera que, para combatir la corrupción, escuelas y familias deben educar en valores pero ello no basta porque los niños y los jóvenes ven a diario cómo se puede hacer dinero robando desde lo alto.

En total, la corrupción nace en gran parte de la corrupción del Estado. El 86\% de encuestados por la Universidad Católica dice que el gobierno es poco o nada eficiente en la lucha contra corrupción. Los principales diarios en el Perú vienen denunciando y alertando repetidamente sobre distintas muestras de corrupción, no solamente en el gobierno nacional, regional y local, también en algunos miembros del Congreso y del Poder
Judicial; no obstante, ¿hay una real preocupación por los riesgos que se ciernen sobre el país si el gobierno no toma en serio la política antinarcóticos y de combate integral al terrorismo (ambos vinculados en la parte operativa), principalmente en el control de los insumos químicos que hoy permiten la producción de más de 300 toneladas de cocaína, y en donde se sospecha que intervienen muchos actos de corrupción?

Los siguientes datos, tomados de la página web de Devida, demuestran que el avance de la lucha contra las drogas es mínimo: de las 56,100 hás sembradas de coca que hay en el país (cálculo del 2008), solo se han logrado erradicar $7,254.8$ hás a octubre de este año; es decir, apenas un $12 \%$. Igualmente, según cifras oficiales, se considera que para producir 302 Tn de cocaína se necesitan unas 30,000 Tn de insumos químicos, por lo que resulta preocupante que solo se hayan destruido 457,674 kg; es decir, casi nada, así como hasta le fecha no se implanta un adecuado sistema de control de los insumos químicos.

En la Convención de las Naciones ONUDO PERU más de cien países, incluido el nuestro, suscribieron un documento que busca fomentar la cultura de rechazo a la corrupción en todas sus formas: burocracia, nepotismo, favoritismo, soborno, fraude, tráfico de influencias, malversación, contribuciones políticas impropias, etc.

En los últimos días del mes de agosto del 2010, el diario Perú 21 informó que el Procurador del Estado hizo llegar al despacho de la Fiscal de la Nación una denuncia que identifica a 116 jueces implicados en irregularidades donde se involucran actos de corrupción.

Con fecha 02 de febrero del 2010 se instaló la Comisión de Alto Nivel de Lucha contra la Corrupción. Por unanimidad, el Presidente del Poder Judicial fue designado Presidente de dicha comisión, que está integrada por personalidades del Foro del Acuerdo Nacional, por el Alcalde de Lima, el Presidente de la CONFIEP, Presidente del Consejo de Ministros, etc. La Comisión se propone impulsar políticas relacionadas con la modernización del Estado, la difusión de los principios éticos, la simplificación de los procedimientos, la fiscalización eficiente, la mayor transparencia y el control ciudadano.

En septiembre del 2010, en el marco del operativo Cóndor que realizó la Contraloría General de la República, se detectaron S/. 350 millones 
involucrados en problemas de corrupción y se determinó que unos 1,000 funcionarios están comprometidos. Así mismo se reveló que dichas acciones de corrupción ocasionaron pérdidas al Estado por un valor de S/. 6,000 mil millones.

El 04 de noviembre del 2010 el Contralor General de la República, en una entrevista en Canal N, expresó que "se ha generalizado una cultura de la coima, la cultura del $10 \%$, pero lamentablemente la cadena contra la corrupción en el Perú no está articulada”, y en el Primer Foro Anticorrupción solicitó que se concedan facultades sancionadoras a la Contraloría General de la República.

\section{LA PERSPECTIVA DEL PRESENTE ESTUDIO}

Nuestra percepción es que la burocracia en el Perú surge desde la misma ley de creación de las entidades públicas, donde se fijan los objetivos generales y específicos, y su finalidad.

La ley de creación sirve para construir la dimensión horizontal del diseño de la organización mediante la "Departamentalización", proceso que tiene como propósito conformar las funciones o campos funcionales. Este elemento lo componen tareas o actividades señalando el quehacer de los órganos de la entidad; vale decir, las tareas que se van hacer o las funciones que se deben cumplir para lograr la realización de sus objetivos. Dichos campos funcionales sirven para conformar los órganos y cargos de la entidad pública, cumpliéndose el principio de que "la función hace al órgano".

Obtener la estructura orgánica básica implica también la construcción de la dimensión vertical de la organización, proceso que consiste en el establecer los niveles organizativos, cadena de mando, jerarquía, los niveles de desconcentración y descentralización institucional.

Toda la información recabada y procesada finalmente está contenida en el Reglamento de Organización y Funciones (ROF), que constituye el instrumento de gestión fundamental normativo que establece formalmente la finalidad, objetivo, naturaleza, denominación, funciones, responsabilidades, autoridad, y las relaciones de dependencia, coordinación y autoridad. La siguiente etapa, según la Guía Técnica para el Diseño de Organizaciones del Instituto Nacional de Administración Pública (INAP), es el diseño de de los sistemas y procedimientos consistente en un conjunto de pasos secuenciales y lógicamente articulados para el ejercicio de las funciones.
El Reglamento de Organización y Funciones (ROF) es un instrumento fundamental: sirve de base para la elaboración de otros instrumentos normativos de gestión, entre ellos el Manual de Organización y Funciones (MOF) y el Cuadro de la Asignación de Personal (CAP). Dichos instrumentos de gestión sirven para la elaboración de los Manuales de Procedimientos (MAPRO) y para la formulación del Texto Único de Procedimientos Administrativos (TUPA).

Con la metodología descrita, obtenemos el modelo burocrático conformando un diseño de organización piramidal, jerarquizado, impersonal por el número exagerado de normas que la regulan, condicionando a una rigidez que limita las capacidades de sus servidores, generando insoportable barreras que hacen que la organización sea vulnerable a la corrupción, además de deteriorar su desempeño en estándares de productividad y competitividad que demanda el mundo cambiante, que exige que las organizaciones cambien con él.

En este trabajo de investigación hemos decidido proponer mecanismos que se orienten a readaptar el modelo organizacional burocrático para responder a una nueva realidad empresarial organizativa, que se distingue por unas características determinadas que asimilan los factores claves de éxito siguientes:

- Adecuación de las estructuras a la nueva situación competitiva en un entorno local, regional y globalizado.

- Adaptación de las organizaciones públicas para alcanzar mayor satisfacción del cliente o usuario.

- Respuesta a la creciente complejidad organizativa y del entorno.

- Respuesta a los requerimientos y producción de servicios con estándares de productividad y calidad satisfactorios.

El camino a seguir para la readaptación a través de la reforma y modernización de la administración pública de la organización burocrática es establecer mecanismos que permitan gradualmente el diseño de una organización horizontal diseñada para brindar una forma estructural y un enfoque organizacional integrado, que permita entregar dicho valor a los clientes o usuarios, potenciando así sus ventajas competitivas. La organización horizontal $\mathrm{y} / \mathrm{o}$ con algunos procesos horizonta- 
lizados promueve una gestión transfuncional, en donde los recursos se trasladan de manera natural a su uso más eficiente, de forma que el trabajo que no aporta valor añadido desaparece.

El modelo de organización que se propone en este estudio implica la readaptación del modelo burocrático a una organización horizontal que se caracteriza básicamente por organizar el flujo de trabajo en torno a procesos claves que abarcan a toda la organización o a parte de ella y que, en última instancia, ligan a ésta con las necesidades del cliente o usuario. Esta propuesta también deviene en reducir la jerarquía y disminuir al máximo el número de niveles organizativos y de áreas en las que se dividen los procesos clave.

El proceso de diseño se efectúa mediante la agrupación de actividades basadas en procesos, así como el proceso técnico de departamentalización se efectúa en base a los procesos claves según su naturaleza, sean estratégicos, operativos de soporte.

Definimos al proceso como un conjunto de actividades que recibe uno o más insumos y genera un producto o servicio con valor agregado para el cliente interno o externo. Igualmente, se define como procesos a un grupo organizado y a sus actividades los que trabajan juntos para transformar la energía en productos o servicio.

Definimos al insumo como el elemento y/o recurso necesario, tangible e intangible, que es incorporado al proceso para obtener un resultado y/o producto y servicio.

El agrupamiento por procesos o departamentalizacion por procesos deriva en una estructura organizativa que promueve y crea las condiciones para el trabajo en equipo multidimensional, además de unificar e integrar cargos y generar una gestión democrática participante. Con tal propósito se constituyen equipos de trabajo conformando las unidades básicas de trabajo, sustituyendo al tradicional cargo o puesto, lo que impulsa un mejor aprovechamiento de la tecnología de la información e informática.

La readaptación al modelo de organización que se está planteando, académicamente se presenta como apto dentro del marco de la administración moderna y estratégica. Toda organización horizontalizada (que no significa organización a un único nivel ni desjerarquizada) está construida sobre dos elementos básicos: trabajo mediante equipos con atribuciones, capacidades y responsabilidad sobre resultados y una dirección orientada hacia procesos.

La readaptación de la organizacional formal que se está proponiendo se sustenta legalmente y fundamentalmente en las Leyes de Modernización del Estado, de Descentralización, del gobierno nacional, gobiernos regionales y gobiernos locales, y específicamente en las Leyes del Procedimiento General Administrativo, Eliminación de las Barreras burocráticas, Simplificación Administrativa, Silencio Administrativo y de las Políticas Nacionales en materia de Simplificación Administrativa (Decreto Supremo N ${ }^{\circ}$ 025-2010-PCM), que modifica el numeral 10 del artículo $2^{\circ}$ del Decreto Supremo $\mathrm{N}^{\circ}$ 027-2007-PCM que define y establece las Políticas Nacionales de obligatorio cumplimiento para las entidades del gobierno nacional.

Cabe destacar que el Decreto Supremo No252010 PCM establece como política nacional los siguientes principios: orientación a la ciudadanía, integralidad de las soluciones, gestión basada en procesos, rigor, mejoramiento continuo y participación ciudadana. Al respecto, podemos inferir que el gobierno peruano está mostrando voluntad política, sentando las bases que favorezcan la readaptación del modelo de organización burocrática hacia un modelo de organización horizontal, en coincidencia con lo que está planteado en el presente estudio.

El presente estudio sostiene que el adecuado soporte técnico para implantar una gestión por procesos parte de conformar una organización formal por procesos, pudiéndose implantar progresivamente con algunos de los procesos de la entidad pública. El modelo de organización burocrático da lugar a un sobre dimensionamiento de puestos o cargos, así como de personal para ocupar dichas posiciones, dando origen al incremento de procedimientos sustantivos y adjetivos .

\section{MODELOS Y CORRIENTES DE REFORMA DEL MODELO BUROCRÁTICO EN UNA PERSPECTIVA ACADÉMICA}

En el 2004 Ben Ross Schneider ${ }^{1}$ publicó en la revista Reforma y Democracia el artículo "La política de la reforma administrativa: dilemas indisolubles y soluciones improbables", donde presenta una clasificación de los modelos y corrientes de

1 Ross Schneider, Ben. (2004). 
reforma del modelo de organización burocrático. A continuación presentamos una síntesis de dicho texto, como un aporte de la parte académica:

\section{Clasificación mediante los modelos:}

a) Weberiano. También denominado reforma del servicio civil. Procura reducir el clientelismo, la corrupción y la politización imponiendo normas generalizadas para regir el comportamiento burocrático, aprobando procedimientos basados en el mérito para el reclutamiento, la promoción, la estabilidad del empleo y, por lo general, aislando a la burocracia de la política.

b) Gerencial. Procura terminar con las ineficiencias y las rigideces de la burocracia mediante la desestimación de una cantidad de reglas, especialmente las concernientes al personal, y garantizando a los administradores o gerentes públicos la discrecionalidad para gerenciar sus departamentos, con la obligación de asumir la responsabilidad por su desempeño.

c) Responsabilización. Este tipo de modelo de reformas reintroducen el control político de la burocracia, pero a través de canales institucionalizados del control Legislativo sobre el comportamiento del Ejecutivo, entendido no solo como poder del estado sino como órgano o ente reformador. Esto puede ser a través de agencias de control horizontal o de control endógeno; en el Perú podría darse mediante la Contraloría General de la República y el sistema de control institucional.

\section{Clasificación mediante las corrientes:}

a) Garantista. Esta corriente reformadora tiene origen en los ideales de libertad y justicia del Estado liberal de derecho. Su objetivo es "la acción sujeta a la ley", o sea al acto administrativo según un marco normativo, no solo que lo regule sino también que lo dirija, considerándolo como medio para la acción. Esta es la visión subyacente en las reformas orientadas a luchar contra la corrupción mediante la "reducción de la discrecionalidad de los operadores públicos" dando un mayor control endógeno, es decir, del mismo sistema, a través de agencias de control en el desempeño de los funcionarios públicos, de carácter horizontal. Esto quiere decir que existe un control paralelo y agencias que tengan el suficiente poder para controlar de manera rigurosa a la función pública, sin importar el rango al que se enfrenta. Esta corriente lleva la impronta de la legalidad y circunscribe a toda estructura o accionar dentro de la administración bajo algún ordenamiento jurídico basada en agencias de control. Por ejemplo, oficinas anticorrupción.

b) Eficientista. La corriente eficientista hace referencia a lo que se conoce como management científico, cuyo patrón de comportamiento viene a ser la conversión de recursos en resultados. Es la corriente que retoma las concepciones clásicas de la administración tales como técnicas de contabilidad y control de gestión, el presupuesto por resultados, análisis financiero, la gestión de las compras y de los inventarios, la clasificación de puestos, la evaluación de cargas de trabajo, etc. Pero esta corriente exige un alto grado de profesionalización de los agentes, además de tener una amplia autoridad para la utilización de los recursos.

c) Contractualista. Esta última corriente se caracteriza por propiciar pautas antiburocráticas de gestión, sin perder de vista la racionalidad económica de los recursos; característica fundamental de la anterior tendencia. Sus fun-

Tabla $\mathbf{N}^{\circ} 1$. Resumen de la clasificación mediante modelos

\begin{tabular}{|l|l|l|l|}
\hline & \multicolumn{1}{|c|}{ Reforma weberiana } & \multicolumn{1}{|c|}{ Reforma Gerencial } & \multicolumn{1}{c|}{ Reforma Responsabilización } \\
\hline Diagnóstico & $\begin{array}{l}\text { Personalismo, clientelismo, } \\
\text { patrimonialismo. }\end{array}$ & $\begin{array}{l}\text { Ineficiencia, papeleo, rigidez, } \\
\text { particularismo. }\end{array}$ & $\begin{array}{l}\text { Abuso de poder, arbitrariedad, falta } \\
\text { de responsabilidad, ausencia de } \\
\text { respuesta. }\end{array}$ \\
\hline Metas & $\begin{array}{l}\text { Universalismo, } \\
\text { profesionalismo, } \\
\text { meritocracia. }\end{array}$ & $\begin{array}{l}\text { Eficiencia, capacidad de } \\
\text { respuesta ante los clientes, } \\
\text { flexibilidad. }\end{array}$ & $\begin{array}{l}\text { Control democrático (directamente } \\
\text { por los ciudadanos o } \\
\text { indirectamente por las legislaturas). }\end{array}$ \\
\hline Caracteristicas & $\begin{array}{l}\text { Rigidez, pérdida de } \\
\text { responsabilidad, } \\
\text { ineficiencia. }\end{array}$ & $\begin{array}{l}\text { Clientelismo, pérdida de } \\
\text { responsabilidad. }\end{array}$ & $\begin{array}{l}\text { Politización, tardanzas excesivas, } \\
\text { procedimientos engorrosos. }\end{array}$ \\
\hline
\end{tabular}


damentos ideológicos son el pensamiento de la, teoría de la elección pública, las teorías de organización empresarial y la moderna teoría económica de la organización. La consecuencia es una visión centrada en sustituir la coordinación jerárquica por una coordinación contractual y más flexible que permita la adaptación de la gestión a circunstancias específicas de la sociedad. Además, ve a la burocracia como un sistema que produce bienes públicos al igual que una empresa produce bienes privados. Consecuentemente se ocupan de imaginar las condiciones bajo las cuales podría maximizarse su producto.

No obstante los distintos enfoques presentados por las entidades que forman parte de la administración pública desde las perspectivas del gobierno nacional, gobiernos regionales y gobiernos locales, así como de sus representantes sobre las barreras burocráticas, nuestra percepción es que la patología de los efectos de las barreras y muestras de corrupción del modelo de la organización burocrática son inherentes a su propia naturaleza de conformación y de sus campos funcionales y, por consiguiente, de su estructura organizativa formal. En tal sentido, describiremos en forma resumida la metodología que se emplea para construir la organización formal burocrática y luego procurar insertar la reflexión de Heide Toflfer que introdujo la idea de la "congruencia", que indicaba que debía haber cierta compatibilidad entre las formas organizativas del sector privado y del sector público para que no se ahoguen entre ambas, dado que ambas formas tienen que coexistir en el tiempo.

\section{MEDIDAS DEL PODER EJECUTIVO Y LEGISLATIVO PARA REFORMAR EL MODELO BUROCRÁTICO}

El gobierno central viene promoviendo la reforma del modelo burocrático, proponiendo el sustento jurídico fundamental en las Leyes de Modernización del Estado, de Descentralización, gobierno nacional, gobiernos regionales y gobiernos locales, y específicamente en la dación de los siguientes dispositivos legales:

- Leyes del Procedimiento Administrativo General.

- Ley de Eliminación de las Barreras Burocráticas.

- Ley de Simplificación Administrativa.

- Ley Marco para el crecimiento de la Inversión Privada.
- Ley del Silencio Administrativo.

- Ley de las Políticas Nacionales en materia de Simplificación Administrativa (Decreto Supremo $\left.\mathrm{N}^{\circ} 025-2010-\mathrm{PCM}\right)$, que modifica el numeral 10 del artículo $2^{\circ}$ del Decreto Supremo № 027 2007-PCM que define y establece las Políticas Nacionales de obligatorio cumplimiento para las entidades del Gobierno Nacional.

Cabe destacar que el Decreto Supremo № 025 2010PCM establece como política nacional los siguientes principios: orientación a la ciudadanía, integralidad de las soluciones, gestión basada en procesos, rigor, mejoramiento continuo y participación ciudadana. Al respecto, podemos inferir que el gobierno peruano está mostrando voluntad política, sentando las bases que favorezcan la readaptación del modelo de organización burocrática hacia un modelo de organización horizontal al horizontalizar algunos procesos. No obstante es importante destacar que, para que se concrete la gestión por procesos, debe antecederla la implantación de la organización formal por procesos.

\section{CONCLUSIONES Y RECOMENDACIONES}

1. Los argumentos presentados nos llevan a la conclusión de que el modelo burocrático de las entidades del sector público genera barreras a las iniciativas privadas y muestran manifestaciones de corrupción originadas por sus características estructurales.

2. El modelo burocrático conforma estructuras organizativas superadas por otras formas de organización, surgiendo la necesidad de proponer herramientas y mecanismos que permitan la readaptacion del modelo burocrático.

3. Ello se puede lograr mediante la reforma y modernización de la administración pública, adoptando modelos alternativos con estándares de productividad y competitividad satisfactorios.

\section{BIBLIOGRAFÍA}

\section{Libros}

ARIZNABARRETA, KOLDO. (2000). "Reivindicación de la reforma administrativa: significado y modelos conceptuales". En: CENTRO LATINOAMERICANO DE ADMINISTRACIÓN PARA EL DESARROLLO (CLAD). Revista Reforma y Democracia. Revista del CLAD. $\mathrm{N}^{\circ} 18$. Octubre del 2000. Caracas, CLAD. 
CARDOSO, FERNANDO HENRIQUE. (1972). Estado y Sociedad en América Latina. Buenos Aires, Nueva Visión.

GARCÍA PELAYO, MANUEL. (1974). Burocracia y Tecnocracia. Madrid, Editorial Alianza.

GOSMAN, ELEONORA. (2005). “Brasil: Destituirían a 18 legisladores de 5 partidos”. En: Diario Clarín. 13 de agosto del 2005. Buenos Aires, Grupo Clarín.

GROISMAN, ENRIQUE. (1988). "Criterios y Estrategias para la Reforma Administrativa”. En: Publicación El Bimestre. Diciembre de 1988. Buenos Aires, Centro Editor de América Latina.

HEGEL, GEORG W.F. (1975). Principios de la Filosofía del Derecho. Buenos Aires, Sudamericana.

HIRSCH, JOACHIM. “Globalización: Transformación del Estado y democracia”. Conferencia realizada en Córdoba. Marzo 1997. Cohete Intituto.

IACOVIELLO, MERCEDES. (1996). "El juego político y las estrategias de Recursos Humanos en las organizaciones públicas”. En: CENTRO DE ESTUDIOS DE POLÍTICA, ADMINISTRACIÓN Y SOCIEDAD (CEPAS). Cuadernos del CEPAS. №4, Septiembre de 1996. Buenos Aires, Diercción de Cepas.

KLITGAARD, ROBERT. (1994). Ajustándonos a la realidad. Buenos Aires, Editorial Sudamericana.

KRIEGER, MARIO y FELCMAN, ISIDORO. (2010). Programa de Reforma Administrativa. Ecuador, Universidad Nacional de Leja.

MAURO, PAOLO. (1997). "Why Worry about Corruption?" En: INTERNATIONAL MONETARY FUND. Economic Issues. №6. Febrero 1997. International Monetary Fund Publication Services

MERTON, ROBERT K. (2002). Teoría y Estructura Sociales. Buenos Aires, Fondo de Cultura Económica.

O ’DONELL, GUILLERMO. (1996). "Otra institucionalización”. En: Revista Agora. $\mathrm{N}^{\circ} 5$. Invierno de 1996, Buenos aires.
OSZLAK, OSCAR. (1999). "Quemar las naves". En: ASOCIACIÓN DE ADMINISTRADORES GUBERNAMENTALES. Aportes, Revista de la Asociación de Administradores Gubernamentales. Año 6. № 14. Argentina, Asociación de Administradores Gubernamentales.

PEGORARO, JUAN. (1999). "La corrupción como cuestión social y como cuestión penal”. En: Revista Delito y Sociedad. №13. Buenos Aires, Revista de Ciencias Sociales.

ROSS SCHNEIDER, BEN.(2004)“La política de reforma administrativa: dilemas insolubles y soluciones improbables". En: CENTRO LATINOAMERICANO DE ADMINISTRACIÓN PARA EL DESARROLLO (CLAD). Revista Reforma y Democracia. № 20. Junio 2004. Caracas, Clad.

SETTEMBRINO, HUGO. (1986). Análisis de la Estrategia de Reforma de la Administración Pública. Buenos Aires, Facultad de Ciencias Económicas de la UNCPBA.

ESTÉVEZ, ALEJANDRO M. (2005). “Reflexiones Teóricas sobre la corrupción: Sus dimensiones política, económica y social”. En: Revista Venezolana de Gerencia. Número 29. Enero-Marzo. Año 10. Maracibo, Universidad de Zulia.

SPENCER, HERBER. (2007). Símbolos de status de la burocracia. En: Revista de la Facultad de Ciencias Empresariales, Uruguay. Universidad Catolica de Uruguay.

Internet

www.ag.org.ar/cepas

www.clad.org.ve

www.claeh.org.uy

www.clacso.edu.ar

EIGEN, PETER. (2003). Presentación del Informe Global de la Corrupción 2003. En: http://www. globalcorruptionreport.org/download/gcr2003/ SPANISH_Introduccion.pdf

www.flacso.edu.ar

www.inap.org. $m x$ 